\title{
PENGARUH DISTRAKSI VISUAL TERHADAP TINGKAT NYERI PADA ANAK USIA PRA SEKOLAH SAAT PEMASANGAN INFUS DI BLUD RSUD H. PADJONGA DAENG NGALLE KABUPATEN TAKALAR
}

\author{
Nurafriani1, Faisal Asdar2, Irmayani3, Hamsinar Haris4 \\ ${ }^{1}$ STIKES Nani Hasanuddin Makassar \\ ${ }^{2}$ STIKES Nani Hasanuddin Makassar \\ ${ }^{3}$ STIKES Nani Hasanuddin Makassar \\ 4STIKES Nani Hasanuddin Makassar
}

Alamat Korespondensi: (sinarharis82@yahoo.com/ 082271152852)

ABSTRAK

\begin{abstract}
Nyeri pada anak merupakan hal kompleks, individual, subjektif dan umum terjadi. Nyeri apabila tidak diatasi membuat anak menjadi tidak kooperatif dan menolak prosedur tindakan sehingga dapat menghambat proses penyembuhan. Pemasangan infus merupakan prosedur invasif yang menyebabkan nyeri pada anak. Distraksi merupakan metode untuk menghilangkan nyeri dengan cara mengalihkan perhatian pada hal lain sehingga anak akan lupa terhadap nyeri yang dialami. Distraksi visual efektif untuk menurunkan nyeri pada anak misalnya menonton video upin-ipin. Tujuan penelitian ini untuk mengetahui pengaruh distraksi visual terhadap tingkat nyeri saat pemasangan infus pada anak pra sekolah. Jenis penelitian ini adalah Pre Ekperimental dengan metode penelitian Intact Group Comparison. Populasi penelitian ini adalah anak usia 3-6 tahun yang dirawat di BLUD RSUD H. Padjonga Daeng Ngalle Kabupaten Takalar. Sampel penelitian sebanyak 30 anak yang ditentukan menggunakan Quota Sampling. Pengukuran nyeri menggunakan skala nyeri FLACC (Face, Legs, Activity, Cry, Consolability). Analisis data menggunakan Uji Independent sample $t$-test. Hasil penelitian ini menunjukkan adanya perbedaan rata-rata skala nyeri dengan nilai signifikan $\rho=0,000(\rho<0,05)$ antara anak yang diberikan distraksi visual dengan anak yang tidak diberikan distraksi visual. Kesimpulan : distraksi visual mempunyai pengaruh yang bermakna terhadap tingkat nyeri anak saat dilakukan pemasangan infus. Saran : anak pra sekolah yang dilakukan pemasangan infus direkomendasikan untuk diberikan distraksi visual menonton video upin-ipin.
\end{abstract}

Kata Kunci : Pemasangan Infus, Tingkat Nyeri, Distraksi Visual

\section{PENDAHULUAN}

Nyeri pada anak merupakan satu hal kompleks, individual, subjektif dan merupakan hal yang umum terjadi. Nyeri apabila tidak diatasi membuat anak menjadi tidak kooperatif dan menolak prosedur tindakan sehingga dapat menghambat proses penyembuhan. Nyeri yang tidak diatasi menyebabkan dampak psikologis lain gangguan perilaku seperti takut, cemas, stress, gangguan tidur selain itu mengurangi koping dan menyebabkan regresi perkembangan (Sarfika, 2015).

Menurut data surveilans World Health Organisation (WHO) dinyatakan bahwa angka kejadian pemasangan infus di rumah sakit khususnya di instalasi gawat darurat cukup tinggi yaitu $85 \%$ per tahun. 120 juta orang dari 190 juta pasien yang di rawat di rumah sakit menggunakan infus (Suprapto, 2015). Angka kesakitan anak di Indonesia adalah 15,26 \%. Angka kesakitan anak di daerah pedesaan sebesar 15,75 \% sementara angka kesakitan anak di daerah perkotaan sebesar $14,47 \%$ (Profil Anak Indonesia, 2015).

Salah satu tindakan yang rutin dilakukan adalah prosedur invasif yaitu pemasangan infus. Prosedur terapi melalui jalur intravena tersebut menimbulkan kondisi nyeri akut bagi anak, artinya nyeri yang dirasakan hanya berlangsung dengan periode waktu yang singkat sekitar 1 menit saat penusukan (Sarfika, 2015).

Walco 2008 dalam Maharani 2018, yang meneliti tentang prevalensi nyeri dan sumber utama penyebab nyeri pada 200 anak yang dirawat di rumah sakit bahwa tindakan pemasangan IV cateter merupakan tindakan pertama yang menyebabkan nyeri dengan hasil $83 \%$ dialami oleh anak usia prasekolah (3-6 tahun).

Salah satu teknik distraksi yang dapat dilakukan pada anak dalam penatalaksanaan nyeri adalah menonton kartun animasi. Pada flim kartun animasi terdapat unsur gambar, warna dan cerita sehingga anak-anak menyukai menonton kartun animasi. Ketika anak lebih fokus 
pada kegiatan menonton flim kartun, hal tersebut membuat impuls nyeri akibat adanya cidera tidak mengalir melalui tulang belakang, pesan tidak mencapai otak sehingga anak tidak merasakan nyeri (Sarfika, 2015).

Penelitian yang dilakukan oleh Sarfika (2015), menunjukkan adanya perbedaan skala nyeri anak yang diberikan teknik distraksi menonton kartun animasi yaitu 2,64 dengan anak yang tidak diberikan teknik distraksi menonton kartun animasi yaitu 6,36 (menggunakan rentang skor FLACC). Penelitian yang dilakukan oleh Yusuf M (2018) bahwa distraksi visual kartu berpengaruh terhadap penurunan tingkat nyeri pada anak selama dilakukan tindakan pemasangan infus.

Berdasarkan data dari BLUD RSUD H. Padjonga Daeng Ngalle Takalar, jumlah pasien anak yang di rawat inap pada bulan Januari 2018 sebanyak 133 anak (16,3\%), Februari 2018 sebanyak 94 anak $(11,5 \%)$, Maret 2018 sebanyak 98 anak 12\%), April 2018 sebanyak 108 anak (13,2\%), Mei 2018 sebanyak 83 anak (10,1\%), Juni 2018 sebanyak 70 anak (8,6\%), Juli 2018 sebanyak 104 anak (12,8\%), Agustus 2018 sebanyak 127 anak (15,5\%).

Berdasarkan latar belakang di atas peneliti tertarik untuk melakukan penelitian dengan judul "Pengaruh Distraksi Visual terhadap Tingkat Nyeri pada Anak Usia Pra Sekolah Saat Pemasangan Infus di BLUD RSUD H. Padjonga Daeng Ngalle Takalar".

\section{BAHAN DAN METODE}

\section{Lokasi, Populasi dan Sampel}

Penelitian dilakukan di ruang perawatan anak BLUD RSUD H. Padjonga Daeng Ngalle Takalar pada tanggal 31 Desember 2018 sampai dengan 13 Januari 2019. Populasi dalam penelitian ini adalah pasien anak usia pra sekolah (3-6 tahun). Sampel diambil dengan menggunakan teknik Quota Sampling, jumlah sampel sebanyak 30 anak. Pengukuran nyeri dengan menggunakan skala FLACC. Sampel tersebut kemudian dipilih berdasarkan karakteristik dan kriteria sampel berdasarkan :

1. Kriteria Inklusi :

a. Anak yang berusia 3-6 tahun.

b. Anak yang dirawat inap.

c. Anak yang akan menerima tindakan pemasangan infus.

d. Bersedia menjadi responden.

2. Kriteria Eksklusi :
a. Anak yang berusia 3-6 tahun.
b. Anak yang dirawat inap.

c. Anak yang akan menerima tindakan pemasangan infus.

d. Bersedia menjadi responden.

Pengumpulan Data

1. Data Primer

Pengumpulan data primer
diperoleh menggunakan lembar
observasi yang telah disediakan oleh
peneliti.

2. Data Sekunder

Pengumpulan data sekunder diperoleh dari Rekam Medik BLUD RSUD H. Padjonga Daeng Ngalle Kabupaten Takalar.

\section{Pengolahan Data}

1. Editing

Memeriksa kembali kebenaran data yang diperoleh.

2. Coding

Pemberian kode numeric terhadap data yang terdiri atas beberapa kategori.

3. Data Entry

Memasukkan data yang telah dikumpulkan ke dalam master tabel computer, kemudian membuat distribusi frekuensi sederhana.

4. Analisa Data

Melakukan analisis, khususnya terhadap data penelitian akan menggunakan ilmu statistic (Hidayat $\mathrm{A}$, 2017).

\section{Analisa Data}

1. Analisa Univariat

Analisa univariat pada umumnya dalam analisis ini menghasilkan distribusi frekuensi dan persentase dari tiap variabel.

2. Analisa Bivariat

Analisa bivariat yang dilakukan terhadap dua variabel yang diduga berhubungan (Hidayat $A, 2017)$.

\section{HASIL PENELITIAN}

Tabel 1. Distribusi Karakteristik Responden di Ruang Perawatan Anak BLUD RSUD H. Padjonga Daeng Ngalle Takalar $(\mathrm{n}=30)$.

\begin{tabular}{|c|c|c|}
\hline $\begin{array}{c}\text { Karakteristik } \\
\text { Responden }\end{array}$ & $\mathrm{n}$ & $(\%)$ \\
\hline Umur & 15 & 50 \\
3 Tahun & 8 & 26,7 \\
4 Tahun & 7 & 23,3 \\
5 Tahun & & \\
\hline Jenis Kelamin & 15 & 50 \\
Laki-laki & 15 & 50 \\
Perempuan & \\
\hline
\end{tabular}


Berdasarkan tabel 1 dari 30 responden sebagian besar berusia 3 tahun terdapat 15 responden $(50.0 \%), 4$ tahun terdapat 8 responden $(26.7 \%)$, dan 5 tahun terdapat 7 responden $(23.3 \%)$ dan terdapat 15 responden $(50.0 \%)$ berjenis kelamin laki-laki dan 15 responden (50.0\%) berjenis kelamin perempuan.

Tabel 2. Distraksi Visual Berdasarkan Kelompok Responden di Ruang Perawatan Anak BLUD RSUD H. Padjonga Daeng Ngalle Takalar

\begin{tabular}{|c|c|c|}
\hline $\begin{array}{c}\text { Kelompok } \\
\text { Responden }\end{array}$ & $\mathrm{n}$ & $(\%)$ \\
\hline $\begin{array}{c}\text { Kelompok } \\
\text { Kontrol }\end{array}$ & 15 & 50.0 \\
\hline $\begin{array}{c}\text { Kelompok } \\
\text { Distraksi }\end{array}$ & 15 & 50.0 \\
\hline Total & 30 & 100.0 \\
\hline
\end{tabular}

Berdasarkan tabel 2 dari 30 responden kelompok kontrol terdapat 15 responden $(50.0 \%)$ dan kelompok distraksi terdapat 15 responden $(50.0 \%)$.

Tabel 3. Distribusi Responden Berdasarkan Skala Nyeri di Ruang Perawatan Anak BLUD RSUD H. Padjonga Daeng Ngalle Takalar

\begin{tabular}{|c|c|}
\hline \multicolumn{2}{|c|}{ Skala Nyeri } \\
\hline Distraksi & Kontrol \\
\hline 3 & 8 \\
\hline 6 & 8 \\
\hline 5 & 6 \\
\hline 5 & 6 \\
\hline 3 & 8 \\
\hline 6 & 7 \\
\hline 6 & 7 \\
\hline 5 & 7 \\
\hline 5 & 7 \\
\hline 5 & 7 \\
\hline 1 & 7 \\
\hline 5 & 7 \\
\hline 4 & 6 \\
\hline 5 & 6 \\
\hline 3 & 7 \\
\hline
\end{tabular}

Berdasarkan tabel 3 menunjukkan bahwa pada kelompok yang dilakukan intervensi (distraksi) sebagian besar responden mengalami nyeri sedang dengan skala nyeri 5 terdapat 7 responden $(46,7 \%)$. Sedangkan pada kelompok kontrol sebagian besar responden mengalami nyeri berat dengan skala nyeri 7 terdapat 8 responden $(53,3 \%)$.
Tabel 4. Ha Hasil Uji Normalitas Data Berdasarkan Skala Nyeri Responden dan Kelompok Responden di Ruang Perawatan Anak BLUD RSUD H. Padjonga Daeng Ngalle Takalar

\begin{tabular}{|c|c|c|}
\hline Variabel & Std. Deviation & Sig \\
\hline $\begin{array}{c}\text { Skala Nyeri } \\
\text { Responden }\end{array}$ & 1,664 & 0,024 \\
\hline $\begin{array}{c}\text { Kelompok } \\
\text { Responden }\end{array}$ & 0,509 & 0,000 \\
\hline
\end{tabular}

Berdasarkan Uji Normalitas Data menggunakan One-Sample KolmogorovSmirnov Test, menunjukkan bahwa data penelitian berdistribusi secara normal dengan nilai Signifikan 0,024 dan 0,000 $<$ Value $(0,05)$.

Tabel 5. Perbedaan Skala Nyeri Pada Kelompok Distraksi dan Kelompok Kontrol di Ruang Perawatan Anak BLUD RSUD H. Padjonga Daeng Ngalle Takalar

\begin{tabular}{|c|c|c|c|c|c|}
\hline Kelompok & $\mathrm{n}$ & Mean & $\mathrm{SD}$ & $\mathrm{t}$ & $\mathrm{p}$ Value \\
\hline Distraksi & 15 & 4,46 & 0,70 & 6,071 & 0,000 \\
Kontrol & 15 & 6,93 & 1,40 & & \\
\hline
\end{tabular}

Tabel 5. Berdasarkan hasil Uji Independent Sample T-Test menunjukkan bahwa rata-rata skala nyeri kelompok distraksi adalah 4.46 (nyeri sedang) dan kelompok kontrol adalah 6.93 (nyeri hebat) dengan selisih 2.46. Nilai Signifikan didapatkan nilai 0,000 dengan demikian nilai $\rho<0,05$. Hasil ini menunjukkan bahwa terdapat perbedaan tingkat nyeri responden yang diberikan distraksi dengan responden yang tidak diberikan distraksi.

\section{PEMBAHASAN}

1. Karakteristik Responden

Distribusi karakteristik responden menurut jenis kelamin menunjukkan jumlah yang sama antara jenis kelamin laki-laki dan perempuan. Karakteristik jenis kelamin ini tidak tidak berpengaruh terhadap respon nyeri anak yang dilakukan pemasangan infus. Menurut Zakiyah (2015) Secara umum pria dan wanita tidak berbeda dalam berespon terhadap nyeri,

Distribusi karakteristik responden menurut umur menunjukkan bahwa responden pada kelompok intervensi dan kontrol sebagian besar berumur 3 tahun $(50,0 \%)$. Usia mempengaruhi persepsi dan ekspresi seseorang terhadap nyeri, perbedaan perkembangan pada orang dewasa dan anak sangat mempengaruhi bagaimana bereaksi terhadap nyeri (Zakiyah, 2015). 
Penelitian ini sejalan dengan penelitian Ulfah, dkk (2014) yang mengatakan bahwa pada usia prasekolah kemampuan dalam menggambarkan bentuk dan intensitas nyeri belum berkembang. Anak usia prasekolah tidak dapat mendefinisikan ruang lingkup tubuh dengan baik dan sedikit pengetahuan mengenai anatomi internalnya.

2. Distribusi Responden Berdasarkan Skala Nyeri Saat Pemasangan Infus Hasil analisis data penelitian menunjukkan bahwa pada kelompok yang dilakukan intervensi (distraksi) sebagian besar responden mengalami nyeri sedang dengan skala nyeri 5 terdapat 7 responden $(46,7 \%)$. Sedangkan pada kelompok kontrol sebagian besar responden mengalami nyeri berat dengan skala nyeri 7 terdapat 8 responden (53,3\%). Menurut International Association for the Study of Pain nyeri merupakan pengalaman emosional yang tidak menyenangkan yang muncul akibat kerusakan jaringan yang actual atau potensial atau digambarkan dalam hal kerusakan sedemikian rupa (NANDA, 2015). Menurut penelitian Iswara (2014) mengatakan bahwa nyeri yang dirasakan bervariasi dalam intensitas dan tingkat keparahan masing-masing anak. Nyeri yang dirasakan mungkin terasa ringan, sedang atau berat. Dalam kaitannya dengan kualitas nyeri, masing-masing anak juga bervariasi. Penelitian ini didukung oleh penelitian Sarfika (2015) yang menyatakan bahwa respon nyeri pada kelompok yang diberi perlakuan menjadi lebih ringan dibandingkan dengan kelompok yang tidak diberi perlakuan.

Distraksi visual merupakan pengalihan perhatian menggunakan pancra indera penglihatan meliputi melihat pertandingan, menonton televisi serta melihat pemandangan (Zakiyah, 2015). Pada penelitian ini memberikan distraksi visual adalah memberikan anak tontonan kartun Upin-Ipin yang disukai oleh anak. Pada saat anak menonton video Upin-Ipin yang memiliki unsur-unsur gambar, warna dan cerita perhatian anak terfokus pada video Upin-Ipin tersebut dan teralihkan perhatiannya dari prosedur pemasangan Infus. Penelitian ini sejalan dengan penelitian yang dilakukan oleh Sarfika (2015) mengatakan bahwa anak-anak menyukai unsur-unsur seperti gambar, warna, cerita dan emosi (senang, sedih, seru dan bersemangat) yang terdapat pada film kartun tersebut merupakan unsur otak kanan dan suara yang timbul dari film tersebut merupakan otak kiri. Sehingga dengan menonton film kartun animasi otak kanan dan otak kiri pada saat yang bersamaan digunakan secara seimbang dan anak fokus pada flim tersebut.

Adanya pengaruh distraksi visual memberikan film kartun Upin-Ipin terhadap penurunan tingkat nyeri pada anak sesuai dengan teori gate control theory, pada saat perawat menyuntikkan jarum, hal tersebut merangsang serabut saraf kecil (reseptor nyeri) sehingga menyebabkan inhibitory neuron tidak aktif dan gerbang terbuka, sementara pada saat yang bersamaan dengan memberikan distraksi berupa flim kartun animasi, yang merangsang serabut saraf besar, menyebabkan inhibitory neuron dan projection neuron aktif. Terapi inhibitory neuron mencegah projection neuron mengirim sinyal ke otak, sehingga gerbang tertutup dan stimulasi nyeri tidak diterima sampai ke otak (Sarfika, 2015).

Hasil penelitian ini sejalan dengan penelitian yang dilakukan oleh Yusuf M (2018) bahwa distraksi visual kartu berpengaruh terhadap penurunan tingkat nyeri pada anak selama dilakukan tindakan pemasangan infus. Penelitian ini sejalan juga dengan hasil penelitin Nova Yanti, dkk (2015) bahwa adanya perbedaan rata-rata skala nyeri yang signifikan antara anak yang diberikan teknik distraksi menonton kartun animasi dengan anak yang tidak diberikan teknik distraksi saat dilakukan pemasangan infus. Terapi bermain dalam bentuk visual sangat efektif untuk anak dapat mengekspresikan emosi dan melepaskan impuls yang tidak dapat diterima oleh anak terutama impuls nyeri (Adriana, 2017).

3. Perbedaan Skala Nyeri Pada Kelompok Distraksi dan Kelompok Kontrol

Berdasarkan Hasil Uji

Independent Sample t-Test menunjukkan adanya perbedaan ratarata tingkat nyeri antara kelompok intervensi yang diberikan distraksi visual dengan kelompok kontrol yang tidak diberikan distraksi visual, dengan nilai signifikan $\rho=0,000$ yang berarti $\rho<$ 
0,05 . Bahwa terdapat perbedaan ratarata tingkat nyeri yang bermakna antara kelompok intervensi dengan kelompok kontrol. Hal ini menunjukkan bahwa distraksi visual berpengaruh terhadap penurunan nyeri saat pemasangan infus pada anak usia pra sekolah (3-6 tahun).

\section{KESIMPULAN}

1. Sebagian besar responden pada kelompok intervensi dan kelompok kontrol berumur 3 tahun.

2. Sebagian besar respon nyeri pada kelompok yang dilakukan intervensi (distraksi) mengalami nyeri sedang. Sedangkan pada kelompok kontrol sebagian besar responden mengalami nyeri berat.

3. Ada pengaruh distraksi visual terhadap tingkat nyeri saat pemasangan infus di
Ruang Perawatan Anak BLUD RSUD H. Padjonga Daeng Ngalle Takalar.

\section{SARAN}

1. Diharapkan kepada pihak Rumah Sakit agar hasil penelitian ini dapat dijadikan acuan dalam terapi nonfarmakologi pada anak saat tindakan invasif terutama pemasangan infus.

2. Diharapkan peneliti selanjutnya dapat melakukan penelitian dengan metode yang berbeda dengan menggunakan jenis distraksi yang lain selain distraksi visual guna meningkatkan ilmu pengetahuan dimasa mendatang agar dapat dijadikan sebagai bahan pustaka untuk penelitian berikutnya.

\section{DAFTAR PUSTAKA}

Bandiyah, S. (2013). Keterampilan Dasar dalam Keperawatan (KDDK). Yogyakarta : Nuha Medika.

Hidayat, Aziz. (2017). Metode Penelitian Keperawatan dan Teknik Analisa Data Edisi I. Jakarta : Salemba Medika.

Iswara, D, A. (2014). Pengaruh Metode Bercerita Dalam Menurunkan Nyeri Pada Anak Prasekolah Yang Terpasang Infus Di Rumah Sakit Islam Surabaya. http://stikeshangtuah.ac.id diunduh pada tanggal 8 Februari 2019

Maharani. (2018). Pengaruh Terapi Bermain Story Telling terhadap Respon Nyeri saat Pemasangan Infus pada Anak di RSUD Pandan Arang Boyolali. Universitas Muhammadiyah Surakarta.

Suprapto. (2016). Hubungan Antara Tingkat pengetahuan perawat Tentang Pemasangan Infus dengan Kepatuhan Pelaksanaan Protap Pemasangan Infus di Instalasi Gawat Darurat RS TK II Pelamonia Makassar. 1 (2), September 2015 : 759-761.

Profil Anak Indonesia. (2015). Angka Kesakitan Anak di Indonesia Tahun 2015. Kementerian Pemberdayaan Perempuan dan Perlindungan Anak (KPP\KPA).

Sarfika, dkk. (2015). Pengaruh Teknik Distraksi Menonton Kartun Animasi Terhadap Skala Nyeri Anak Usia Prasekolah Saat Pemasangan Infus di Instalasi Rawat Inap Anak RSUP DR. M. DJAMIL Padang. Jurnal Ners Keperawatan, 1 (11), Maret $2015: 32-40$.

Ulfa, S. (2014). Penurunan Respon Maladaptif Anak Prasekolah Menggunakan Story Telling Book : Seri Pemasangan Infus Di RSUD Kabupaten Jombang. http://googleusercontent.com diunduh tanggal 5 Februari 2019.

Zakiyah, A. (2015). Nyeri Konsep dan Penatalaksanaan dalam Praktik Keperawatan Berbasis Bukti. Jakarta : Salemba Media 